\title{
La Guerra Civil en los programas de producción propia de la Televisión de Galicia
}

\section{The civil war in the production programs of Television de Galicia}

\author{
Mercedes Román Portas. Universidad de Vigo \\ Aurora García González. Universidad de Vigo
}

Recibido: 13-VI-2013 - Aceptado: 18-IX-2013

Resumen:

Este trabajo intenta ofrecer una relación exhaustiva de los programas de producción propia emitidos por la Televisión de Galicia sobre la Guerra Civil. Se incluyen documentales, series de ficción, u otras fórmulas de programas (debates, talks shows, etc.). Este material se ha analizado con el fin de conocer cómo se ha ido transmitiendo, y en qué medida ha podido estar teñido por enfoques ideológicos o culturales. Sobre esos análisis se ha elaborado el texto correspondiente. La TVG es una televisión autonómica, de titularidad pública, que inició sus emisiones el 24 de julio de 1985. Desde entonces los directores de la compañía han ido cambiando al compás de los cambios en la presidencia de la Xunta de Galicia. La metodología incluye el visionado de 1.520 minutos (alrededor de 25 horas) de cinta pertenecientes al archivo DOPO (documentos de producción propia emitidos) de la TVG. Dentro de este archivo, se realizó una selección previa de todos aquellos documentos cuya sinopsis o minutaje incluyera los términos “Guerra Civil”. Un total de 96 documentos. Una vez revisados los documentos escritos que contenían toda la información sobre los distintos documentales o reportajes, se borraron de la lista aquellos en los que la Guerra Civil era simplemente mencionada (no tratada).

Palabras clave:

Televisión; Guerra Civil; producción propia; Galicia; comunicación

Abstract:

This paper attempts to provide an exhaustive list of produced programs broadcast by Televisión de Galicia about the Civil War. This includes documentaries, drama series, or other forms of programs (debates, talk shows, etc..). This material has been analyzed in order to know how it has been passed, and how much has been able to be colored by ideological or cultural approaches. On such discussion is written the text. The TVG is a regional television, public ownership, which began broadcasting on July 24, 1985. Since then the directors of the company have been changing in step with changes in the presidency of the Xunta de Galicia. The methodology includes the viewing of 1,520 minutes (about 25 hours) of tape from the archives DOPO (self-produced documents issued) of the TVG. Within this file, there was a pre-selection of all documents whose synopsis includes the words "Civil War". 96 documents total. After reviewing the written documents that contained all the information about the various documentaries or stories, were deleted from the list those in which the Civil War was just mentioned (untreated).

Key Words:

Television; civil war; productions; Galicia; communication

doxa.comunicación | n 17, pp. 189-206 | 


\section{Introducción}

El discurso histórico con el que la televisión en España ha intentado reconfigurar una y otra vez la memoria colectiva e histórica de los ciudadanos acerca de la Guerra Civil ha sido heterogéneo, cambiante, en absoluto apolítico y, sobre todo, muy dependiente de las necesidades e intereses del presente (Hernández Corchete, 2012: 18).

Aún es posible sostener que las investigaciones académicas sobre aquella lucha fratricida siguen siendo escasas. Máxime si se tienen en consideración la cantidad de producciones de carácter informativo y documental que se han emitido, sin interrupción, tanto en TVE como en las cadenas autonómicas y privadas durante las últimas décadas. Estas producciones se han lanzado al imaginario social, propiciadas principalmente por las políticas de la memoria, que pretendieron una constante activación del recuerdo colectivo (Aróstegui, 2006).

No obstante hay que admitir el esfuerzo investigador realizado, principalmente en los últimos años en los que algunos trabajos monográficos han intentado una aproximación al conocimiento científico de este conflicto (Hernández, 2007; López, 2009; Montero y Paz, 2011 y Hernández Corchete, 2012). Todos ellos con la finalidad de contribuir de alguna manera a la interpretación de la Guerra Civil dado el carácter fugaz o la natural tendencia de la televisión de hacer de sus contenidos un espectáculo.

Quizás el ámbito menos desarrollado haya sido el análisis de las televisiones autonómicas aunque no faltan importantes contribuciones como los relatos televisivos sobre la guerra en Cataluña y el País Vasco estudiados por Enrique Castelló y Santiago de Pablo (Hernández, 2012) respectivamente para que las memorias alternativas sirvieran también de recuerdo de la identidad colectiva de las audiencias autonómicas a las que iban dirigidos. Este es el marco en que se encuadra este artículo, que viene a completar el estudio del relato televisivo en las comunidades autónomas.

En el presente trabajo se aborda una aproximación a la comunidad autónoma de Galicia. Las investigaciones realizadas sobre la televisión de otras comunidades autónomas se han centrado más en el estudio de series de ficción o en documentales y otras producciones elaboradas expresamente sobre la Guerra Civil.

Nuestra hipótesis de partida fue que la información sobre el conflicto bélico ofrecida por la TVG ha podido estar teñida por enfoques ideológicos o culturales que en alguna medida podrían haber sesgado la información de esta televisión autonómica lo que podría haber afectado a la percepción de los receptores sobre ese acontecimiento histórico.

El objetivo general de este estudio era intentar ofrecer una relación exhaustiva de los programas de producción propia emitidos por la Televisión gallega que incluyeran cualquier referencia sobre la Guerra Civil. El material analizado se corresponde con el total de la producción propia desde el comienzo de las emisiones de TVG (1985) hasta el momento actual (2013). Se han incluido documentales, series de ficción, u otras fórmulas de programación (debates, talks shows, etc). Y todo 
este material se ha analizado con otros dos objetivos particulares: conocer cómo se ha ido transmitiendo, y en qué medida ha podido estar teñido por enfoques ideológicos o culturales, el contenido elaborado acerca del conflicto bélico.

La TVG es una televisión autonómica, de titularidad pública, que inició sus emisiones el 24 de julio de 1985 (Maneiro, 2012). Dada su dependencia de los organismos públicos, suele presentar variaciones en la dirección y también en la estrategia de programación y contenidos cuando se producen cambios en la presidencia del gobierno autonómico. Por ello resulta apropiado adjuntar un cuadro como el siguiente que sintetiza los cambios sucedidos en este período:

Cuadro 1. Directores de la TVG (1985-2013)

\begin{tabular}{|c|c|c|}
\hline Años & Director CRTVG & Presidente Xunta de Galicia \\
\hline $1985-1986$ & Luis Losada & \multirow{2}{*}{ Gerardo Fernández Albor (AP) } \\
\hline $1986-1987$ & Lois Caeiro & \\
\hline $1987-1990$ & Abilio Bernardo de Quirós & Fernando González Laxe (PSdeG) \\
\hline $1990-1994$ & Ramón Villot & \multirow{2}{*}{ Manuel Fraga Iribarne (PP) } \\
\hline $1994-2005$ & Francisco Campos & \\
\hline 2005-2009 & Benigno Sánchez & Emilio Pérez Touriño (PSdeG) \\
\hline $2009-$ & Alfonso Sánchez Izquierdo & Alberto Núñez Feijoo (PP) \\
\hline
\end{tabular}

Fuente: CRTVG y elaboración propia

Con esta clasificación temporal a la vista se emprendió la tarea de rastrear la posible relación entre los contenidos elaborados por la TVG y los responsables del Gobierno autonómico en cada etapa.

\section{Metodología}

La investigación comenzó por localizar, con ayuda del personal del servicio de documentación que actualmente trabaja en la TVG, los archivos en que se registran los materiales, tanto de producción propia como ajena, y materiales de información como ficción, en cualquiera de los formatos. Así se localizaron cuatro archivos:

DOPO: Programas de Producción Propia

BRUT: Brutos de grabación 
CINT: Documentos elaborados guardados en el archivo, no necesariamente emitidos tal cual, sino compactados de brutos (pueden ser brutos de algún programa emitido)

PALL: Programas de Producción Ajena

Para este trabajo se han empleado únicamente los materiales procedentes del archivo DOPO. El trabajo incluyó una selección previa de todos aquellos documentos cuya sinopsis o minutaje incluyera los términos “Guerra Civil”. Se obtuvieron un total de 96 documentos.

Una vez revisados los documentos escritos que contenían la información completa sobre los distintos documentales o reportajes, se eliminaron de la lista aquellos en los que la Guerra Civil era simplemente mencionada (no tratada).Y se procedió al visionado de las cintas: un total de 1.520 minutos (alrededor de 25 horas).

Tras el visionado de las cintas, se eliminaron también materiales cuyas menciones a la Guerra Civil fueran solo verbales (sin imágenes, narraciones o entrevistas relacionadas que desarrollaran mínimamente el tema), por considerar que no aportaban ninguna información, ni sobre el objeto de estudio en sí mismo, ni sobre el enfoque o posicionamiento adoptado por los realizadores de estos trabajos o por la propia TVG.

El listado final incluyó 40 documentos (el equivalente a 222 minutos de emisión).

Estos documentos fueron analizados de la siguiente manera: En primer lugar se clasificaron por tema. Existen algunos documentos cuyo tema central es la propia Guerra Civil. En estos casos se procedió al análisis del documento completo. En aquellos casos (la mayoría) en los que las menciones a la Guerra Civil eran puntuales (y por tanto, mucho más breves), se realizó el análisis de cada espacio concreto. Aquellos documentos que presentaban varias menciones a la Guerra Civil, repartidas a lo largo del metraje (independientes, por tanto, entre sí) fueron divididos en bloques, relacionando cada bloque con una mención puntual.

Para completar el análisis, se elaboró un libro Excel en el que se clasificaron los datos en torno a los siguientes ítems:

1. palabras clave identificadas en los distintos documentos,

2. contexto (político, social y cultural) en el que se realizaron las emisiones,

3. temas generales tratados en los 40 programas y

4. menciones al nacionalismo realizadas

También se confeccionó un cuadro general con todos los datos relativos a cada uno de los documentos (título, programa en el que se incluye, fecha de emisión, referencia en archivo, género, tema general del documento, minutos dedicados a 
la Guerra Civil, tema concreto dentro de este campo, contextualización, temas en los que insiste, palabras clave y referencias al nacionalismo, así como un breve comentario acerca de las imágenes de archivo que se incluyen).

De los datos consignados en este libro Excel proceden los gráficos que se han insertado en este trabajo.

\section{Resultados: La Guerra Civil en los programas de producción propia de la TVG}

\section{1. Términos clave identificados en los distintos documentos}

Para comenzar el trabajo se localizaron los términos empleados con más frecuencia a lo largo de los programas estudiados. Del total del visionado (222 minutos emitidos en la TVG sobre la Guerra Civil) se seleccionaron 27 palabras (incluidos sinónimos) que resultaron ser las más repetidas y las que mejor definen la idea que transmitir en cada programa.

Las que con mayor frecuencia aparecen se corresponden con un concepto negativo de la Guerra Civil. El "refugio" o el "exilio" son términos muy utilizados para referirse a las consecuencias del conflicto en Galicia. En la mayoría de las entrevistas, es el propio entrevistado quien cuenta en primera persona el sufrimiento del destierro. Es constante también el empleo de estos términos en biografías de artistas o personalidades políticas cuando aluden a esta temática en sus obras o publicaciones.

Cuadro 2. Términos clave

\begin{tabular}{|l|l|}
\hline Palabras & No de repeticiones \\
\hline Refugio/exilio/destierro & 14 \\
\hline Asesinato/muerte/masacre/tragedia/fusilamiento & 10 \\
\hline Miedo/terror/tragedia/tristeza/crueldad & 10 \\
\hline Campos de concentración/prisión/reclutamientos & 9 \\
\hline Régimen/dictadura/movimiento nacional/franquismo/golpistas & 8 \\
\hline República & 8 \\
\hline Represión & 8 \\
\hline Memoria & 6 \\
\hline Guerrilla/milicia/resistencia & 6 \\
\hline Miseria/pobreza & 5 \\
\hline Investigación & 5 \\
\hline Galleguismo & 4 \\
\hline
\end{tabular}




\begin{tabular}{|l|l|}
\hline Palabras & No de repeticiones \\
\hline Mártires & 3 \\
\hline Entusiasmo & 3 \\
\hline Lucha & 3 \\
\hline Estatuto & 2 \\
\hline Progresismo/esperanza & 2 \\
\hline Argentina & 2 \\
\hline Literatura/poesía & 2 \\
\hline Comunismo/Rusia & 2 \\
\hline Derechos & 2 \\
\hline Justicia & 2 \\
\hline Plebiscito & 1 \\
\hline Desigualdad & 1 \\
\hline Cunetas & 1 \\
\hline Socialismo & 1 \\
\hline Patriotismo & 1 \\
\hline
\end{tabular}

Fuente: Archivo CRTVG y elaboración propia

También son muy frecuentes las palabras "asesinato" o "fusilamiento" y "tristeza", "miedo" o "crueldad" (cada una de ellas se repite al menos 10 veces). En un 50 \% de los programas analizados aparecen estos términos como claves a la hora de interpretarlos.

Resulta interesante que en nueve de los 40 programas revisados se mencionen en algún momento conceptos como "reclutamiento", "prisión" o “campos de concentración”. Cobra importancia la Isla de San Simón, convertida en prisión durante ese tiempo, en la que fueron recluidos numerosos presos del bando republicano, fundamentalmente de las zonas próximas; refleja lo que ocurría en Galicia durante la Guerra Civil.

Palabras como "dictadura franquista" y "República" son igualmente de uso frecuente. Y coincide el número de veces que aparece cada una (ocho menciones). La imparcialidad en el posicionamiento de muchos de los reportajes hace que estas ideologías no resulten tan relevantes como se esperaba al inicio de la investigación. 
Otros términos que se repiten son "memoria" (seis menciones), "investigación" (en cinco programas) y "galleguismo" (cuatro veces). Algunas de estas palabras cobran fuerza no por el número de veces que se reiteran en los programas sino por el significado interpretativo que aportan al visionado. Ocurre lo mismo con los términos "entusiasmo", "lucha", "esperanza", "literatura", "derechos" o "justicia".

\subsection{Contexto (político, social y cultural) en el que se realizaron las emisiones}

Se buscó igualmente establecer una clasificación de los materiales de la investigación, que tuviera alguna significación por el contexto cultural, social o político del momento en que se emitieron.

A lo largo del periodo analizado (1985-2013), cuatro agrupaciones políticas presidieron la Xunta de Galicia (Alianza Popular, PsdeG-PSOE, PP y el bipartito PSdeG-PSOE/BNG).

Al intentar una aproximación a la influencia que cada uno de estos partidos, durante su mandato, hubiera podido tener sobre el enfoque y duración de las emisiones relacionadas con la Guerra Civil dentro de la producción propia de la TVG, cabe destacar que no se apreciaron variaciones significativas entre los cuatro gobiernos (cinco, si distinguimos la legislatura de Manuel Fraga de la de Alberto Núñez Feijoo, ambos del PP). De manera casi proporcional al número de años que cada grupo ha gobernado la comunidad.

Cuadro 3. Partido político en el gobierno en el momento de emisión de los programas sobre la Guerra Civil

\section{PARTIDO POLÍTICOEN EL MOMENTO DE EMISIÓN DE LOS PROGRAMAS SOBRE LA GUERRA CIVIL}

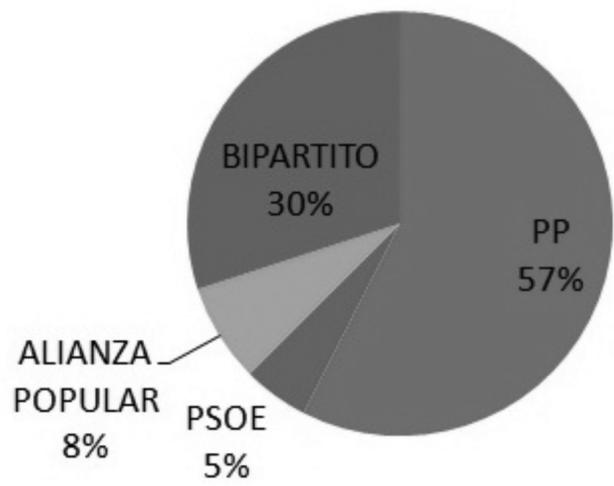

Fuente: Archivo CRTVG y elaboración propia 
La Guerra Civil parece constituir un "comodín temático", tal y como muestra el siguiente cuadro. Se estudiaron separadamente las posibles influencias en cuanto al número de emisiones según el partido que estuviese en el gobierno, tanto a nivel autonómico como a nivel general. El porcentaje se estableció sobre el total de años que lleva funcionando la TVG.

Cuadro 4. Porcentaje de referencias a la Guerra Civil según gobierno autonómico

\begin{tabular}{|l|l|l|l|l|l|l|}
\hline $\begin{array}{l}\text { Partido en el } \\
\text { poder }\end{array}$ & \multicolumn{2}{|l|}{ Años en el poder (27) } & \multicolumn{2}{l|}{ No de menciones a la Guerra Civil } & \multicolumn{2}{l|}{ Duración en minutos de la mención } \\
\hline Alianza Popular & $2(1985-1987)$ & $7,41 \%$ & 3 & $(5 \%)$ & 21 & $(9,46 \%)$ \\
\hline PSdeG-PSOE & $3(1987-1990)$ & $11,11 \%$ & 2 & $(5 \%)$ & 9 & $(4,05 \%)$ \\
\hline PP & $\begin{array}{l}18(1990-2005,2009- \\
2012)\end{array}$ & $66,67 \%$ & 23 & $(57,6 \%)$ & 123 & $(55,41 \%)$ \\
\hline Bipartito & $4(2005-2009)$ & $14,81 \%$ & 12 & $(30 \%)$ & 67 & $(30,18 \%)$ \\
\hline
\end{tabular}

Fuente: Archivo CRTVG y elaboración propia

Podría decirse que la media de emisión de contenidos sobre la Guerra Civil durante los gobiernos de AP, PsdeG-PSOE y PP es de, aproximadamente, 1,14 emisiones/año. No ocurrió lo mismo en el caso del gobierno bipartito encabezado por Emilio Pérez Touriño durante los años 2005/2009, en los que esta media aumenta hasta las 3 emisiones/año (debido, con toda probabilidad, al debate y posterior aprobación, en el año 2007, de la Ley de Memoria Histórica).

Al estudiar esta misma relación en términos del gobierno central (repartido, a lo largo de estos años, entre PSOE y PP) sí se observa alguna diferencia entre el número de emisiones realizadas durante el gobierno socialista y el popular, como se puede apreciar en el cuadro № 5 , aunque se descartó la existencia de una posible relación causal que explique este hecho.

Cuadro 5. Porcentaje de referencias a la Guerra Civil durante los gobiernos del PSOE y del PP

\begin{tabular}{|l|l|l|l|l|l|l|}
\hline $\begin{array}{l}\text { Partido en el } \\
\text { poder }\end{array}$ & \multicolumn{2}{|l|}{ Años en el poder } & \multicolumn{2}{l|}{ No de menciones a la Guerra Civil } & \multicolumn{2}{l|}{ Duración en minutos de la mención } \\
\hline PSOE & $\begin{array}{l}18(1985-1996, \\
2004-2011)\end{array}$ & $66,67 \%$ & 27 & $(67,5 \%)$ & 163 & $(73,42 \%)$ \\
\hline PP & $\begin{array}{l}9(1996-2004, \\
2011-2012)\end{array}$ & $33,33 \%$ & 13 & $(32,5 \%)$ & 59 & $(26,58 \%)$ \\
\hline
\end{tabular}

Fuente: Archivo CRTVG y elaboración propia 
Tampoco se identifican diferencias en función del partido gobernante, en cuanto al enfoque desde el que se ha tratado la Guerra Civil en todos los documentos analizados.

Todos los materiales estudiados, tanto documentales como reportajes, ofrecen un idéntico tratamiento de los temas, articulado por medio del discurso de narradores y personalidades entrevistadas. En todos ellos existen coincidencias en los siguientes puntos:

- $\quad$ Rechazo frontal hacia la Guerra Civil como un capítulo trágico de la historia de Galicia.

- $\quad$ Crítica al sistema represivo que forzosamente estaba ligado a esta etapa.

- $\quad$ Identificación de la Guerra Civil como un periodo de retroceso para la cultural gallega y el galleguismo, así como para la autonomía y la autodeterminación política del pueblo gallego.

- $\quad$ Memoria Histórica.

El enfoque dado a la Guerra Civil se centra, casi siempre, en el aspecto cultural, por lo que, a pesar de que las figuras sobre las que versan estos documentos (o aquellas que son entrevistadas) habitualmente expresan sus inclinaciones políticas lejos de la imparcialidad, no se aprecia un choque de intereses (o ideologías) entre los contenidos emitidos por la TVG y los distintos partidos que gobiernan la comunidad. Incluso podría hablarse de una aparente falta de relación entre los documentos emitidos y el contexto político gallego, que tal vez represente una cierta independencia de la TVG con respecto al poder político.

En la mayor parte de los casos, son acontecimientos sociales o culturales ajenos al ámbito político los que justifican el qué, el cuánto y el cuándo de las emisiones. Existen casos en que las referencias a la Guerra Civil no parecen motivadas por ningún acontecimiento señalado. Son casos en los que la guerra y sus consecuencias no tienen protagonismo en la narración, pero que surgen en el curso de un relato más amplio y dada su importancia cobran relevancia y la mención es inevitable. Pero, con todo, más de la mitad de las emisiones (67,5\%) están justificadas por un hecho concreto y actual, que se considera de interés para la ciudadanía.

Sin duda, el acontecimiento que con mayor claridad ha influido en el aumento de la producción y emisión de documentales y reportajes en los que se toca el tema de la Guerra Civil a los largo de estos años es la Ley de Memoria Histórica. Esta Ley tenía una relación directa con la Guerra Civil, pues se reconoce y amplía derechos y establece medidas en favor de quienes padecieron persecución o violencia durante ese período por parte de los sublevados y durante la dictadura posterior. Y además, fue noticia durante un dilatado periodo de tiempo ya que se prestó atención televisiva tanto a los debates previos, la aprobación del proyecto de ley y la declaración del Año de la Memoria Histórica en el 2006, como a la aprobación de la Ley en el Congreso de los Diputados en el año 2007, y las denuncias, críticas y estudios posteriores. 
Ocho de las 40 emisiones estudiadas, responden a esta motivación, a pesar de que se trata de un lapso de tiempo muy limitado dentro de los 27 años analizados.

Cuadro 6. Emisiones sobre la Guerra Civil en torno a eventos concretos

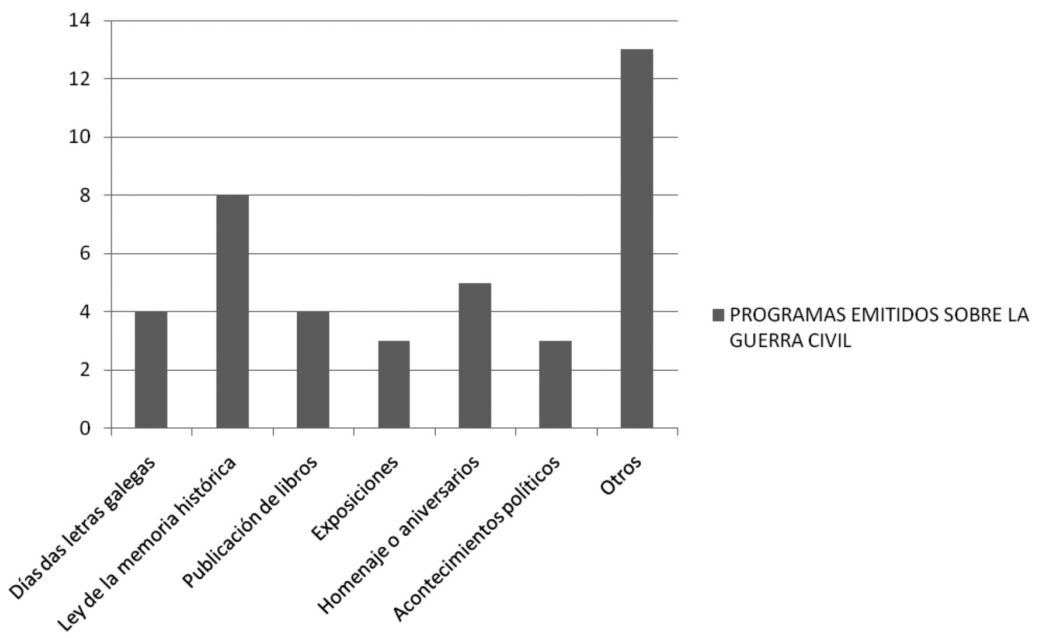

Fuente: Archivo CRTVG y elaboración propia

Otras cinco emisiones, aunque no directamente relacionadas con esta ley, también están vinculadas con la memoria histórica. Se trata de programas realizados con intención de homenajear o celebrar el aniversario de algún acontecimiento o personaje público (político o cultural) asociado, de algún modo, a la Guerra Civil.

Se contabilizaron además tres emisiones sobre exposiciones que, aunque no constituyen un homenaje manifiesto, recuerdan algunos acontecimientos relacionados con este capítulo de la Historia.

La literatura siempre ha tenido un peso notable en la historia de Galicia. En torno a la Guerra Civil, ocho programas recogieron acontecimientos relacionados con el universo literario gallego. Este universo está presente en un altísimo porcentaje de los documentos analizados, pero con menor relieve: cuatro de estos programas celebran el Día das Letras Galegas y la vida y la obra de los literatos a los que se dedica esta fecha. La historia personal de estos personajes está siempre vinculada a la Guerra Civil y la posguerra, tal y como reflejan los documentos. Otras cuatro emisiones se deben a la publicación de algún libro (novela o ensayo) en el que la Guerra Civil tiene protagonismo.

Como ya se ha comentado, los acontecimientos políticos no tienen un peso específico entre los motivos que llevan a producir o emitir un documento en el que se trate algún aspecto de la Guerra Civil: solo tres de las 40 emisiones coinciden 
de algún modo con el ámbito político (elecciones, movilización social), pero no eran estos acontecimientos el motivo de la emisión.

El resto de los documentos estudiados (13), vinculados en el momento de su emisión con la aprobación de leyes, problemáticas de interés social, polémicas propiciadas por otros medios, no ofrecen evidencias acerca del motivo de su emisión.

\subsection{Temas}

La TVG ha prestado atención en estos programas a diferentes asuntos, todo ellos en torno a la Guerra Civil. Se han clasificado tomando como referencia el tiempo total dedicado a cada uno de los temas.

El asunto "La Guerra Civil en España” es el tema general que más se trata en todos los programas de producción propia analizados. Así lo reflejan los siguientes gráficos:

Cuadro 7. Tiempo dedicado a la Guerra Civil en minutos

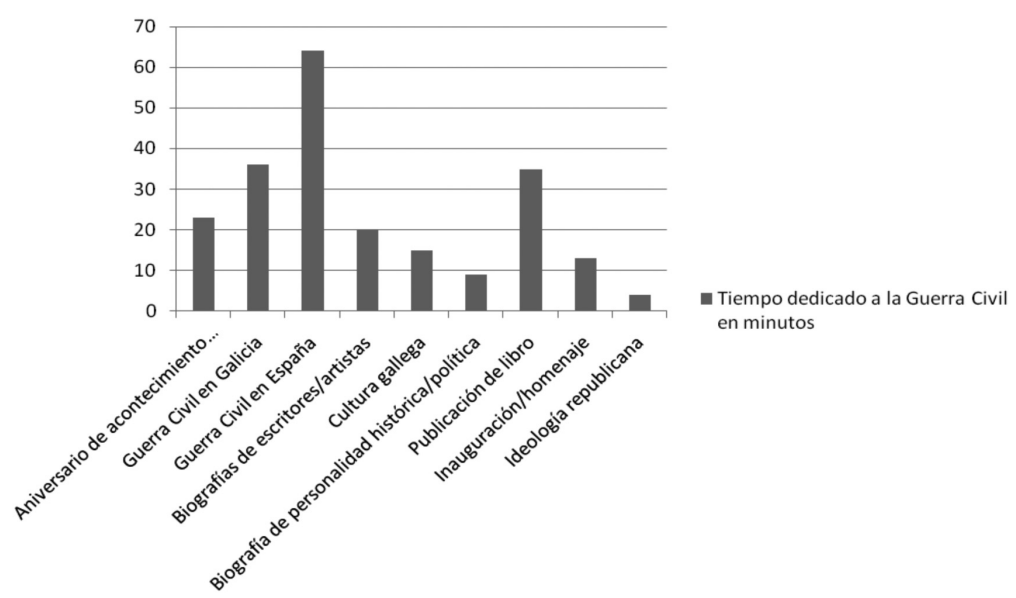

Fuente: Archivo CRTVG y elaboración propia 
Cuadro 8. Número de repeticiones de un mismo tema

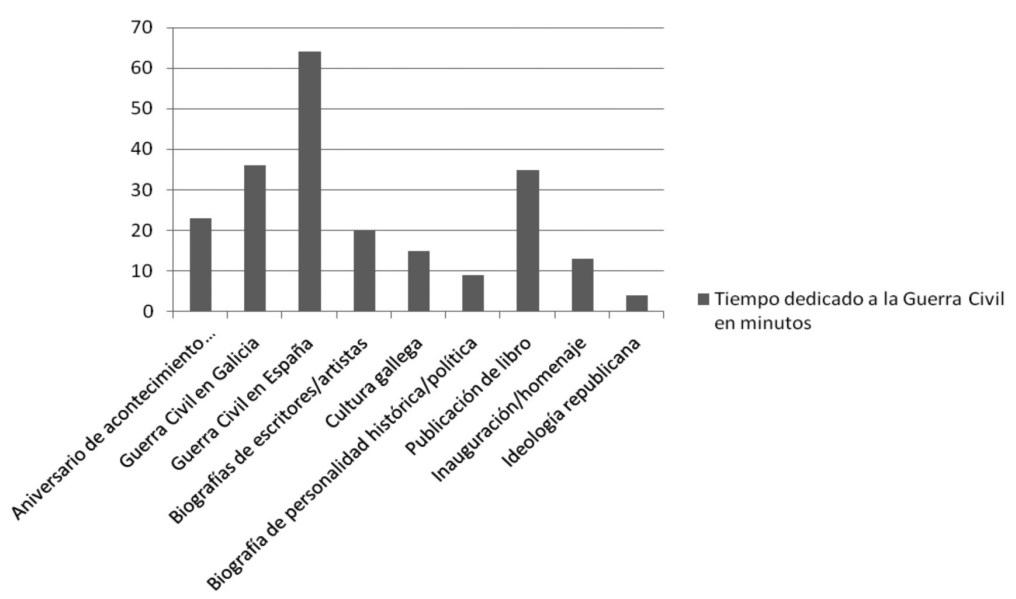

Fuente: Archivo CRTVG y elaboración propia

Este tema de la Guerra Civil en España ocupa en total 64 minutos de los 222 revisados. La mayor parte corresponde a un reportaje emitido en abril de 1994 sobre las reservas de oro del Banco de España que salieron de Madrid hacia Moscú en 1936 y no volvieron nunca.

El motivo para emitir estas imágenes parece ser coyuntural, es decir aparece al ofrecer la biografía de alguna persona anónima (la mujer más anciana de España, un gaitero asturiano...) o al repasar una época que lleva a hablar de la Guerra Civil (el siglo XX en España, importancia cultural y social del año 1956, el Wolfram tras el cese de la Guerra...) no por este hecho en sí.

En estos programas, el posicionamiento es en la mayoría de los casos republicano, con numerosas críticas al franquismo a través de las entrevistas a víctimas, a familiares que vivieron la posguerra o a personas influidas de alguna manera por la misma.

Resulta interesante la selección de imágenes de archivo sobre la Guerra Civil que se realiza para cada reportaje o documental. A lo largo de todo el análisis las imágenes se repiten constantemente pero cobran mayor fuerza según el programa donde estén incluidas.

En las biografías se incluyen imágenes de casas destruidas, niños o de algo que refleje la tristeza del exilio. En los reportajes de carácter histórico se muestran planos menos sensibles y más duros como los aviones, las bombas, los civiles luchando o los asesinatos. En cuanto a las imágenes de Franco aparecen en pocas ocasiones cuando se habla de la Guerra Civil en España. 
El segundo tema al que más tiempo se dedica es la "Guerra Civil en Galicia”. Son 36 minutos repartidos en cinco programas que pretenden reflejar las repercusiones de este acontecimiento en la comunidad y lo hacen a través de los testimonios de sus protagonistas. Se trata de gallegos exiliados o refugiados que recuerdan cómo vivieron en primera persona los acontecimientos. En este contexto destaca un reportaje sobre la historia de la Universidad de Santiago de Compostela, en el que se dedican seis minutos a explicar la represión tras el estallido de la Guerra Civil y su efecto negativo en la educación y la cultura. Ramón Piñeiro, uno de los entrevistados asegura que "la tensión previa al golpe en Galicia era inferior a la del resto de España porque nadie se esperaba la represión que finalmente hubo". También se dedica bastante tiempo a la historia de la Isla de San Simón como prisión durante la guerra. El ambiente que rodea a esta temática es la miseria, el aislamiento, la clandestinidad y el retroceso que sufrió la comunidad gallega durante la Guerra Civil.

Es constante en estos programas el uso de imágenes y dibujos de artistas de la época como Castelao, Luis Seoane o Manuel Colmeiro para transmitir la tristeza y el sufrimiento de aquella época. En cuanto a las imágenes de archivo que más se emplean son casas destruidas, bombardeos, niños sufriendo, gente corriendo por la calle y marineros.

Dentro de la temática "publicación de libros", aunque sólo aparece en tres programas, hay 35 minutos dedicados a la Guerra Civil. En realidad este tiempo se podría incluir también en la "Guerra Civil en Galicia” ya que las publicaciones tratan sobre esta comunidad, sin embargo, estos tres programas tienen la única finalidad de dar a conocer los libros. Los autores son el historiador gallego Victor Santidrián (por su publicación del diario del soldado republicano Casimiro Jabonero en el que relata la existencia de un campo de prisioneros en Lavacolla), el escritor Xesús Alonso (por sus publicaciones Os escritores galegos ante a Guerra Civil Española 1936-1939 y Intelectuais marxistas e militantes comunistas en Galicia 19262006) y Federico Cocho (por su libro Guerra Civil. Qué pasou en Galicia e en España).

La miseria, los fusilados, y el drama, entre otras, son palabras muy empleadas en esta temática, que también refiere la labor de investigación y la dificultad por parte de estos escritores para recuperar la memoria histórica de Galicia. Al recordar la comunidad gallega en época de guerra Federico Cocho hace referencia a la existencia de una "democracia sin demócratas" y asegura que "en Galicia no hubo guerra pero sí mucha represión”.

En seis programas emitidos por la TVG para conmemorar el "aniversario de algún acontecimiento político o histórico" hay 23 minutos dedicados exclusivamente a la Guerra Civil española. La celebración del Año de la Memoria Histórica en el 2006 es el hecho más relevante. En todas estas emisiones surge la idea de revelar todo lo que se sepa sobre lo ocurrido desde el estallido de la guerra en 1936 hasta la muerte de Franco. Uno de los reportajes reivindica el estudio de la Guerra Civil desde una perspectiva propia de Galicia.

También se emitió un Especial Informativo con motivo del 50 aniversario del Estatuto de Autonomía en el que aparecen imágenes de la guerra. Y en el programa Parlamento, un debate acerca de la proposición de ley de la recuperación de la me- 
moria histórica de la mujer. En esta temática se repiten las imágenes de archivo de niños, pobreza o marineros, pero también se introducen palabras como esperanza, galleguismo o investigación, algo que se podría explicar por el entusiasmo que provocó en muchos la puesta en marcha de la ley de la Memoria Histórica.

En varios de los programas analizados se hace referencia a “escritores y artistas” que vivieron la Guerra Civil española y, de hecho, hay siete programas dedicados exclusivamente a sus biografías. Pero el tiempo que dedican a hablar de esta época (1936-1939) es casi insignificante: una media de tres minutos por programa. Muchos se centran más en sus vivencias durante la posguerra y en el exilio. Castelao, Luis Pimentel, Rafael Dieste, Roberto Blanco Torres, Seoane, Arturo Souto e Isaac Díaz Pardo son los protagonistas de las biografías. Los programas hacen mucho hincapié en la lucha de estos artistas por el Estatuto de Autonomía, y sobre todo en cómo vivieron el exilio, el refugio o la prisión en algunos casos. Las imágenes de archivo más repetidas son de asesinatos, desfiles, bombardeos, manifestaciones, aviones y niños sufriendo. También acompañan dibujos, obras y caricaturas de los artistas reflejando en la mayoría de los casos tristeza y miedo.

Muy similar a esta temática es la dedicada a la "Cultura gallega”, centrada en las consecuencias de la Guerra Civil en la literatura de esta comunidad. Tres programas muestran la lucha de los artistas por mantener los valores culturales con especial referencia a la ciudad de Buenos Aires como principal refugio de los exiliados. Son 15 minutos dedicados a la Guerra Civil con imágenes de exiliados y de obras de los referentes culturales.

Se contabilizaron también cuatro programas dedicados a "Inauguraciones y homenajes" que ocupan en total 13 minutos cuyo tema principal suele ser un homenaje a republicanos fusilados. No hay ninguna emisión de estas características antes del año 2003 y las más importantes se producen tras la aprobación de la Ley de la Memoria Histórica.

Otros cuatro programas se refieren a "biografías de personalidades histórica/política”. Tres de ellos se emitieron en días consecutivos entre el 21 y el 25 de febrero de 2003. Se trata del programa “Galegos de Honra” que aborda el tema de la Guerra Civil sin demasiada profundidad. De hecho solo hay dedicados nueve minutos a este tema. Son las figuras de Xesús Canabal, Manuel Meilán y Bibiano Fernández Osorio-Tafall. Una vez más el exilio y el galleguismo aparecen como palabras clave en esta parte, y no así el sufrimiento de la guerra y los asesinatos.

Por último cabe aludir a un programa que podría clasificarse como "Ideología republicana" por tratarse de una entrevista con la finalidad de mostrar la fidelidad del entrevistado a sus ideas políticas. El personaje es Manuel Corral, miembro del partido socialista condenado a muerte dos veces y encarcelado durante 22 años por su ideología. La entrevista, incluida en el programa “Corazonada”, se emitió el 27 de julio de 1989. En ese momento en la Xunta de Galicia gobernada el PSdeG con Fernando González Laxe como presidente. 


\subsection{Nacionalismo}

En lo tocante a las referencias al nacionalismo en las piezas analizadas, se encuentran menciones al mismo en nueve de las 40 emisiones ( $22 \%$ en total).

Cuadro 9. Referencias al nacionalismo

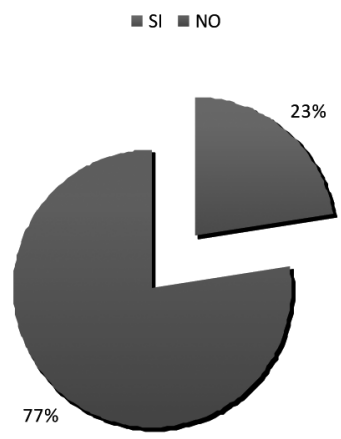

Fuente: Archivo CRTVG y elaboración propia

El término "nacionalismo", de hecho, apenas es empleado en estos documentos. Se hace mención, en estos casos, al llamado "galleguismo", que se refiere al movimiento de defensa de la cultura y la identidad gallegas surgido a mediados del s.XIX. Este movimiento mantuvo su actividad en los siglos siguientes y hasta nuestros días de la mano, especialmente, de grandes figuras culturales, algunas de las cuales protagonizan varios de los vídeos analizados, aunque “ignorando”, en cierto modo, su vertiente más política. Los documentos se centran en el aspecto más cultural del galleguismo, entre otras cosas porque las personalidades entrevistadas pertenecían más a este ámbito que al político.

Las emisiones analizadas sí hacen especial hincapié en el tema de la cultura gallega, y en la defensa de la identidad, la lengua y la creación artística y literaria; pero limitan las menciones al galleguismo como movimiento político especialmente activo, sobre todo desde el exilio, durante la Guerra Civil y el franquismo. El término galleguismo, como se ha visto, sí figura entre las palabras clave más repetidas en los distintos documentos.

Sobre los temas centrales que motivan la mención al galleguismo, destacan aquellos programas centrados en la propuesta, aprobación popular por plebiscito y posterior freno (motivado por el estallido de la guerra) del Estatuto de Autonomía.

Casi la mitad de las menciones al galleguismo/nacionalismo (un 45\%), proceden de cuatro programas en los que se aborda directamente el movimiento desde esta perspectiva, en el contexto de las presiones realizadas por los miembros del movimiento galleguista para conseguir el "sí” popular al Estatuto en el verano de 1936. En segundo lugar, encontramos menciones al galleguismo político (un el 33\%), que fue un tema tratado en tres de los 40 documentos. Por último, y con 
un enfoque mucho más centrado en el ámbito cultural y desde una perspectiva más amplia, hay una mención al galleguismo/nacionalismo como tema base de muchas figuras literarias de la época (11\%), y otra mención a la importancia del galleguismo dentro de la defensa del plurinacionalismo español (11\%).

Cuadro 10. Tipo de referencias al nacionalismo

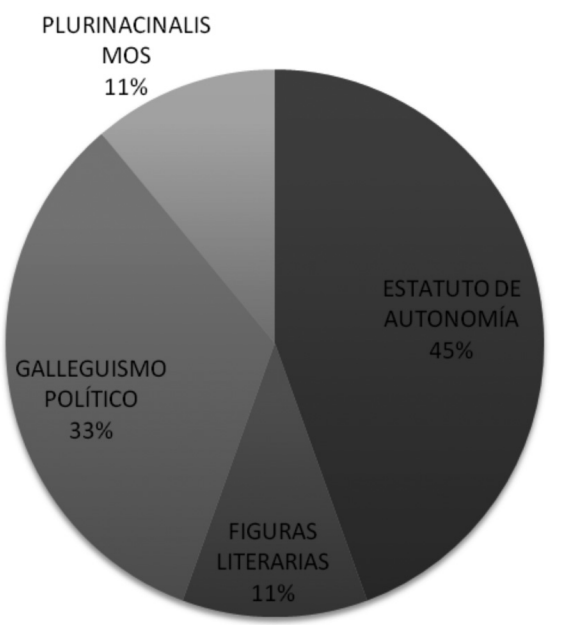

Fuente: Archivo CRTVG y elaboración propia

\section{Conclusiones}

Este trabajo abre una vía a la investigación que, por razones de espacio y oportunidad, no era posible desarrollar exhaustivamente en esta ocasión. Por tanto las conclusiones que aquí se enumeran, son una síntesis muy ajustada de la parte sometida a medición cuantitativa y algunas inferencias que esta medición ha hecho posibles. En suma, se corresponden únicamente con el trabajo de análisis y clasificación realizado sobre el material disponible de uno de los archivos de la TVG, que contiene los programas de producción propia que tuvieron como tema la Guerra Civil española, y del que cabe extraer al menos las siguientes conclusiones:

- Casi un tercio (32\%) de los documentos analizados abordan el estallido del conflicto y sus posteriores consecuencias desde una perspectiva estatal, planteando sus contenidos como "Guerra Civil en España”. Sin embargo, y aún siendo el enfoque "Guerra Civil en Galicia" menos tratado (36 minutos, que suponen el 18\% del total), los documentales y reportajes emitidos por la TVG hacen referencia en todo momento al caso gallego por distintas vías. Se refieren a acontecimientos de la historia de Galicia contemporáneos a la guerra como la aprobación popular del Estatuto de Autonomía, o la publicación de títulos destacados de la literatura gallega. Se ofrecen también testimonios de ciudadanos, siempre gallegos, que vivie- 
ron aquella etapa y se reflejan acontecimientos ocurridos en Galicia en aquella época, con ocasión de la celebración de aniversarios u homenajes.

- En la TVG apenas existen documentos que encaren este capítulo de la Historia de forma directa. En la mayoría de los casos, la Guerra Civil aparece como parte de una biografía, o al repasar una etapa determinada. Podría decirse que de forma tangencial o residual. Este dato resulta revelador cuando menos de una cierta prudencia en el modo de afrontar el estudio de esta conflictiva etapa.

- El universo cultural gallego artístico y literario vertebra buena parte de los documentos analizados. En algunos casos, los documentos muestran biografías de personalidades destacadas en las que, inevitablemente, la Guerra Civil merece una referencia; en otros casos, esas mismas personalidades o sus amistades y allegados al abordar temas diversos (algunos de corte político), ofrecen un testimonio, que aporta información sobre el momento histórico.

- La Guerra Civil se muestra en todos los documentos como un capítulo negativo de la historia de España, se trata como tal en todo momento. A pesar de que no se ha abordado directamente, el conflicto bélico, es posible asegurar que no es imparcial la imagen que la TVG ofrece de los distintos bandos, ni el número de documentos que dedicó a cada uno de ellos. La mayoría de los documentales y reportajes están protagonizados por el bando republicano y las personalidades destacadas que militaban en el mismo. En ellos son presentados como estandartes de la cultura y el progreso, mientras que el bando sublevado es mostrado como destructor (de futuro, de poblaciones, de familias, de cultura...). De los 40 documentos analizados, sólo uno se dedica a la biografía de un personaje relevante del ejército nacional.

- No se han identificado diferencias destacables en el tratamiento del tema (ni en el número de emisiones relacionadas con él) en función del partido político que gobernase Galicia en las distintas épocas. La media de programas emitidos durante el período de gobierno de cada partido es muy similar salvo en el caso del bipartito PsdeG-PSOE/BNG, cuya media de emisiones sobre la Guerra Civil es más del doble que los anteriores, posiblemente por coincidir con la Ley de la Memoria histórica.

- En lo tocante a los acontecimientos sociales o culturales que hayan podido influir en las emisiones, destaca claramente la Ley de Memoria Histórica. También coincide la emisión de estas piezas con homenajes o aniversarios que, de forma directa o indirecta, guardan relación con la Guerra Civil (por tratarse de personalidades relevantes o fechas clave de esta época) o con acontecimientos literarios, con especial atención a la celebración del Día das Letras Galegas.

- Las referencias al nacionalismo en los documentos analizados son escasas, y casi siempre realizadas desde un enfoque más cultural que político, con menciones al galleguismo y sus principales protagonistas, antes, durante y después de la Guerra Civil. En este sentido, el Estatuto de Autonomía centra buena parte de las referencias. 
En todo caso la historia de la Guerra Civil, contada por la TVG, no puede separarse del contexto social y político en que se produjo. Y resultará también interesante analizar el resto de archivos de los materiales que conserva, tanto de producción ajena como elaborados pero no emitidos, para completar la visión histórica que aportan.

\section{Referencias bibliográficas}

Aróstegui, J y Godicheau, E. (eds.) (2006): Guerra civil, mito y memoria. Madrid: Marcial Pons.

Carabante, J. (2009): “Memoria histórica, pretérito politizado”, Aceprensa. 7/I/2009. Disponible en: http://www.aceprensa.com/articles/memoria-historica-preterito-politizado/

Castelló, E. (ed.) (2012): La mediatización del conflicto político. Discursos y narrativas en el contexto español. Barcelona: Laertes.

- "Memoria en conflicto. Guerra Civil y posguerra en los documentales de la televisión catalana", en Hernández Corchete, S. (ed.) (2012): La Guerra Civil televisada. Salamanca: Comunicación Social.

De Pablo, S. (2012): “¿Invasión o conflicto fratricida? El País Vasco y la Guerra Civil en Euskal Telebista”, en Hernández Corchete, S. (ed.) (2012): La Guerra Civil televisada. Salamanca: Comunicación Social.

Hernández Corchete, S. (2007) "La voluntad democratizadora de las series documentales históricas producidas por Televisión Española en los años ochenta”, en Moreno et. al. (eds.): Los desafíos de la televisión pública en Europa. Pamplona: Eunsa.

LEY 52/2007, de 26 de diciembre, por la que se reconocen y amplían derechos y se establecen medidas en favor de quienes padecieron persecución o violencia durante la guerra civil y la dictadura. (BOE no 310, de 27/12/2007).

Maneiro, A. (2012): 25 anos de Televisión de Galicia. De 1985 a 2010. Santiago de Compostela: Asociación de Periodistas de Galicia (APG).

Montero, J. y Paz, Ma A. (2011): “The Spanish Civil War on Televisión Española During the Franco Era (1956-1975)”, Comunicación y Sociedad, vol XXIV, n² 2, pp. 149-197

Pablo, S. de (2012): “Guerra Civil”, en Pablo, Granja, Mees y Casquete (eds.): Diccionario ilustrado de símbolos del nacionalismo vasco. Madrid: Tecnos.

Román Portas, M. (2005) "La televisión local en España", Sphera Publica, nº 5, pp. 229-239. 